\title{
UMA PROPOSTA DE APLICAÇÃO DE CHECKLIST DE AVALIAÇÃO DA QUALIDADE COMO MECANISMO DE MELHORIA DA GESTÃO DE CURSOS DA EAD NO EXÉRCITO BRASILEIRO.
}

RIO DE JANEIRO/RJ MAIO/2018

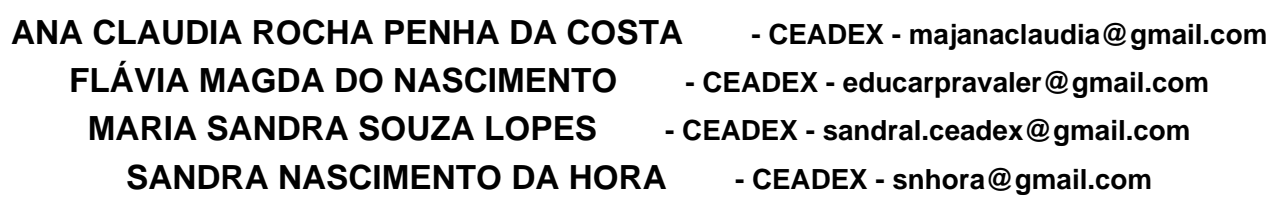

Tipo: Relato de Experiência Inovadora (EI)

Categoria: Métodos e Tecnologias

Setor Educacional: EDUCAÇÃO CORPORATIVA

\begin{abstract}
RESUMO
Este trabalho, estudo de caso com foco no planejamento da melhoria da qualidade, a partir do desenvolvimento do projeto Sistema de Avaliação da Qualidade na Educação a Distância (EAD) do Exército Brasileiro (SAQ - EAD EB) apresenta a proposta de aplicação de um instrumento investigativo para cursos, estágios e programas na EAD, denominado "Checklist de Avaliação da Qualidade como Mecanismo de Melhoria da Gestão de cursos da EAD no EB". Inicialmente, contextualiza o cenário do Sistema de Ensino do Exército (SEE), do qual participa o Centro de Educação a Distância do Exército (CEADEX), organização militar (OM) responsável pela modalidade EAD no Exército. Nestes processos, o SAQ-EAD EB, projeto institucional possui dentre outras ações, visando à tomada de decisão dos escalões superiores, a etapa de levantamento de informações necessárias ao processo existente na ponta da linha (OM que executam a modalidade EAD). Para fins de realização de um recorte do cenário a ser estudado, face a complexidade estrutural do SEE, a proposta de aplicação deste Checklist, nesta etapa, apenas contempla as dimensões e variáveis que se relacionam ao segmento educação profissional, dentro da estrutura corporativa. Optou-se pela apresentação de parte da metodologia a ser aplicada na busca de dados da qualidade dos processos de EAD nos estabelecimentos de ensino (Estb Ens) elou organizações do Exército (OM) com encargos de ensino. $O$ instrumento proposto foi construído a partir de pesquisas sobre indicadores de qualidade nos Referenciais de Qualidade para a Educação Superior a Distância, na resolução do Conselho Nacional de Educação/Câmara de Educação Superior (CNE/CES) ambos do MEC, no Instituto Nacional de Estudos e Pesquisas Educacionais Anísio Teixeira (Inep) para o ensino superior, bem como nas normatizações de ensino do EB. Traz ao final expectativas do planejamento para a melhoria da qualidade na $E A D$, como contribuição à educação corporativa, ensino profissionalizante para o EB.
\end{abstract}

Palavras-chave: qualidade, gestão, EAD, educação corporativa

\section{AGRADECIMENTOS}

A TODOS ÀQUELES QUE DE MANEIRA DIRETA OU INDIRETA COLABORAM E COLABORARAM COM A CONSECUÇÃO DESTA PESQUISA. 


\section{Introdução.}

O ensino no Exército Brasileiro (EB) "compreende as atividades de educação, de instrução e de pesquisa, realizadas nos estabelecimentos de ensino, institutos de pesquisa e outras organizações militares com tais incumbências" e é regulado pelo Sistema de Ensino do Exército (SEE), definido em Lei no 9.786, de 8 de fevereiro de 1999, que dispõe sobre o Ensino no EB e dá outras providências. Este sistema, conforme o Art. $1^{\circ}$ possui "[...] características próprias com a finalidade de qualificar recursos humanos para a ocupação de cargos e para o desempenho de funções previstas, na paz e na guerra, em sua organização". Integram, portanto, o SEE "os cursos, estágios e outras atividades de interesse do Exército, realizados por seu efetivo em organizações estranhas à sua estrutura, militares ou civis, nacionais ou estrangeiras", bem como cursos, estágios e graduações, realizados fora do seu sistema de ensino, para a qualificação de seus quadros, segundo legislação pertinente. Fundamenta-se basicamente, nos seguintes princípios: integração à educação nacional; seleção pelo mérito; profissionalização continuada e progressiva; avaliação integral, contínua e cumulativa; pluralismo pedagógico; aperfeiçoamento constante dos padrões éticos, morais, culturais e de eficiência; e titulações e graus universitários próprios ou equivalentes às de outros sistemas de ensino. Desta forma, o SEE realiza o ensino profissionalizante e escolar, sendo estruturado em graus, linhas e ciclos de ensino para os quais têm-se a escolaridade das diferentes atividades de ensino e correlação com os níveis funcionais militares, as áreas de concentração dos estudos e das funções militares e o grupamento de atividades de ensino necessárias à progressão na carreira militar. (BRASIL, 1999).

O SEE operacionaliza o ensino presencial e a distância, assim como um misto destas formas de promover educação para cursos, estágios e ou programas de ensino nas modalidades de qualificação: formação (inicial, básica para ocupação de cargos e desempenho de funções de menor complexidade em cada segmento da carreira militar, entre outros); graduação (em profissões de nível superior, com ou sem correspondentes civis, para a ocupação de cargos e para o desempenho de funções militares); especialização (para a ocupação de cargos e para o desempenho de funções que exijam conhecimentos e práticas especializadas); extensão (para ampliação de conhecimentos e as técnicas adquiridos anteriormente, necessários para a ocupação de determinados cargos e para o desempenho de determinadas funções); aperfeiçoamento (para atualização e ampliação dos conhecimentos obtidos com a formação ou a graduação, necessários para a ocupação de cargos e para o desempenho de funções de maior complexidade); altos estudos militares (para a ocupação de cargos e para o desempenho de funções privativas do Quadro de Estado-Maior da Ativa); e preparação 
(amplia, sedimenta e uniformiza conhecimentos, bem como qualifica para o ingresso em determinados cursos). (Ibidem)

Do exposto, considerando a multiplicidade de modalidades a serem conduzidas no SEE, no ensino presencial ou a distância, suas peculiaridades e desafios, está em construção um projeto de avaliação da qualidade - SAQ - EAD EB, que visa atender à melhoria da qualidade dos processos e produtos gerados na EAD do Exército em seus diversos graus, linhas e ciclos de ensino, visando melhor qualificar os recursos humanos para a ocupação de cargos e para o desempenho de funções previstas no Exército Brasileiro, bem como o uso racional desta modalidade, considerando a capilaridade da distribuição dos efetivos do EB ao longo de todo o país, as peculiaridades regionais e a possibilidade de utilização pela família militar. (EXÉRCITO BRASILEIRO, 2012, p. 8).

\section{Objetivos.}

- apresentar parte da metodologia a ser aplicada na avaliação da qualidade no SAQEAD EB; e

- apresentar um Checklist para a busca de dados da qualidade dos processos de EAD nos estabelecimentos de ensino (Estb Ens) e/ou organizações (OM) do EB com encargos de ensino (EXÉRCITO BRASILEIRO, 2014).

\section{Metodologia.}

Este trabalho envolveu, a realização de uma pesquisa bibliográfica, visando buscar subsídios para a construção de um arcabouço inicial, como referencial de parâmetros indispensáveis para a avaliação da qualidade da EAD, a partir dos Referenciais de Qualidade para a Educação Superior a Distância do MEC (MEC, 2007), da normatização expedida pelo Conselho Nacional de Educação/Câmara de Educação Superior do MEC, Resolução CNE/CES no 1, de 11 de março de 2016 que estabelecem Diretrizes e Normas Nacionais para a Oferta de Programas e Cursos de Educação Superior na Modalidade a Distância (MEC, 2016), considerados também indicadores obtidos a partir das pesquisas via Instituto Nacional de Estudos e Pesquisas Educacionais Anísio Teixeira (INEP, 2016) para o ensino superior, e por fim, de forma a adequar este arcabouço à realidade da EAD no Exército foram observadas as políticas institucionais vigentes, tais como Portarias, Normas e Diretrizes de ensino que tratam do ensino no Exército Brasileiro, comum às modalidades presenciais e a distância.

Da pesquisa realizada foi construída uma tabela (Checklist) contendo as dimensões de controle para a busca de dados da qualidade dos processos de EAD nos Estb Ens e/ou 
OM com encargos de ensino que será apresentado como instrumento de aplicação, mecanismo de Avaliação da Qualidade como Mecanismo de Melhoria da Gestão de cursos da EAD no EB. Este Cheklist será inserido no Portal de Educação do Exército (http://www.portaldeeducacao.eb.mil.br/), no formato de questionário online, a fim de ser respondido pelos agentes de ensino, seu preenchimento será obrigatório com data limite de entrega. Os dados coletados serão analisados pela Divisão de Educação a Distância do CEADEx (DEAD) e o resultado desta análise seguirá ao Escalão Superior como forma de relatório, contendo planos de ação e proposição de melhorias na EAD, segmentado pelas áreas de competências de cada órgão dentro do SEE.

No tocante ao público alvo, este trabalho consequentemente, destina-se à melhoria do trabalho dos agentes de ensino do EB, profissionais que possuem relação direta e/ou indireta com o processo de gestão de cursos, estágios, programas e capacitações continuadas institucionais.

\section{4. $O$ estudo de caso, contextualização.}

No SEE a organização militar responsável pela gestão dos processos educacionais na modalidade a distância no Exército Brasileiro é o Centro de Educação a Distância (CEADEx), criado em $1^{\circ}$ de julho de 2015. O CEADEx tem a finalidade descrita na Diretriz para a Implantação do Centro de Educação a Distância do Exército (EB20D-01.026), Portaria oㅜ 308 - EME (Estado-Maior do Exército), de 23 de novembro de 2015 que trata de: a) Dotar o Sistema de Educação e Cultura do Exército (SECEx) de uma OM que atue na coordenação e orientação da modalidade da educação a distância (EAD); e b) Contribuir com o processo de capacitação dos recursos humanos no âmbito do Exército. Na mesma Diretriz, é atribuída como uma das missões do CEADEx "colaborar com as Diretorias/Centros, Estb Ens Subd e Centros de Instrução (Cl), com a manutenção dos padrões de qualidade da modalidade de EAD". E assim, atender à demanda do Planejamento Estratégico do Exército, consubstanciada nos Planos Estratégicos de 2015-2018 e 2016-2019, proporcionando maior sinergia e racionalização no preparo de profissionais, otimizando a formação, o aperfeiçoamento e a extensão/especialização de militares do Exército.

O CEADEx é, portanto, a organização que deve olhar para todo o cenário educacional do Exército e realizar propostas de implantação de uma política de qualidade que vise a melhoria dos processos de oferta da modalidade de EAD, de forma complementar as ações educacionais da modalidade presencial, realizadas pelos estabelecimentos de ensino, a exemplo de escolas como a Escola de Sargentos das Armas (EsSA) e/ou OM com encargos de ensino, como o próprio CEADEx que qualifica os agentes de ensino do 
Exército em cursos de capacitação continuada de curta duração para atuar nos perfis necessários à modalidade a distância.

Neste aspecto, e para melhor compreender os critérios de qualidade selecionados como itens de pesquisa sugeridos no instrumento proposto, sob o formato de um checklist, é importante conhecer a relação do CEADEx com as OM de ensino e/ou de encargos de ensino. O CEADEx está diretamente subordinado a Diretoria de Educação Técnica Militar (DETMIL), entretanto esta diretoria somente possui a responsabilidade de um dos segmentos do ensino militar, pois é subordinada ao Departamento de Educação e Cultura do Exército (DECEx) que normatiza a educação no Exército no tocante as linhas Bélica, de Saúde e Complementar. Este departamento possui a gestão do ensino de 03 (três) diretorias e um Centro, a saber: Diretoria de Educação Preparatória e Assistência (DEPA) que garante ao EB integração à educação nacional no tocante ao ensino fundamental e médio, Diretoria de Educação Superior Militar (DESMII) que trata dentre outros aspectos de titulações e graus universitários próprios ou equivalentes às de outros sistemas de ensino, Diretoria de Educação Técnica Militar (DETMII) que trata da profissionalização continuada e progressiva, Centro de Capacitação Física do Exército (CCFEx) que trata das questões de performance física do integrante do EB e Diretoria do Patrimônio Histórico e Cultural do Exército (DPHEx) que trata da vertente cultural e preservação do patrimônio histórico e divulgação da história militar.

Assim sem prejuízo para os trabalhos realizados, o CEADEx possui uma situação privilegiada em termos de Canal Técnico que permite, estando sob a gestão da DETMII, interagir com as demais diretorias na mesma linha de subordinação desta, a fim de apoiar e prover soluções para todos os tipos de segmentos da Educação no EB. Vale, ainda, considerar que o sistema de Educação e Cultura do Exército (SECEx) está dentro do escopo do SEE e sob força de lei possui os princípios de seleção pelo mérito; avaliação integral, contínua e cumulativa; pluralismo pedagógico; aperfeiçoamento constante dos padrões éticos, morais, culturais e de eficiência, dos quais todas as Diretorias, Centros e OM subordinadas são afetos.

\section{Apresentação dos resultados.}

Neste sentido, e visando colaborar com a melhoria da qualidade da EAD no EB, em termos de educação profissionalizante, na oferta de cursos, estágios e programas para um público alvo estritamente adulto, como recorte desta pesquisa, está sendo delineado um projeto de melhorias dos processos de gestão de EAD pelas equipes multidisciplinares no CEADEx que visa organizar e padronizar o modus operandis dos processos e produtos para a gestão de EAD. Como primeiro objetivo deste trabalho tem- 
se a apresentação de parte da metodologia a ser aplicada na avaliação da qualidade no SAQ-EAD EB, uma vez que o projeto encontra-se em curso e em termos de planejamento, optou-se por permitir reavaliar resultados, em um formato espiral, para que conforme a aplicação dos instrumentos de coleta dos dados, estes possam subsidiar nova decisão, correções de rumo, consequentemente ações de melhoria nos processos e produtos gerados na EAD.

Desta forma, no planejamento do projeto SAQ - EAD EB foram definidos objetivos e metas de curto, médio e longo prazo para a fase inicial de sua implantação, foram identificadas linhas de ação básicas, assim como a escolha do projeto piloto de melhoria, dentre duas escolas de referência no âmbito da DETMII, a Escola de Instrução Especializada do Exército (EsIE), que atua com EAD desde 2012, no Curso de Habilitação ao Quadro Auxiliar de Oficiais (CHQAO) e a Escola de Sargentos de Logística (EsSLog) que inicia seu planejamento de oferta de EaD para 2019.

Como segundo objetivo deste trabalho apresenta-se o Checklist, uma tabela em contínua construção, instrumento de coleta de dados que será aplicado como mecanismo de captação de informações sobre as dimensões que envolvem a gestão dos processos de EAD, podendo ser melhorada conforme observação de sua aplicação na rotina diária das $\mathrm{OM}$. Os dados observados na coleta servem de base para a revisão das ações previamente delineadas no projeto, com base nas dimensões pesquisadas. Esta tabela foi composta para servir de instrumento de aplicação, mecanismo de Avaliação da Qualidade como Mecanismo de Melhoria da Gestão de cursos da EAD no $E B$, a partir dos indicadores pesquisados pelo MEC, em seus referenciais de qualidade, tais como "Concepção de educação e currículo no processo de ensino e aprendizagem; Sistemas de Comunicação; Material didático; Avaliação; Equipe multidisciplinar; Infraestrutura de apoio; Gestão Acadêmico-Administrativa; e Sustentabilidade financeira" (MEC, 2007).

Além disso, e para retratar a realidade educacional do Exército foram trabalhadas, inicialmente as dimensões de qualidade que definem a organização institucional para $E A D$, os agentes de ensino (profissionais com papéis educativos ou de gestão), as instalações físicas que compõem a infraestrutura a disposição da EAD, as questões legais e normativas institucionais e as diretrizes pedagógicas (EXÉRCITO BRASILEIRO, 2010). A seguir apresenta-se a lista de itens que compõe a tabela - Checklist contendo as dimensões de controle para a busca de dados da qualidade dos processos de EAD nos Estb Ens e/ou OM, bem como a análise das características encontradas: NC - não conforme, OM - oportunidades de melhorias e CO conforme. 
1. Organização Institucional para EAD: a) O Estb Ens possui em seu projeto pedagógico a inclusão da modalidade EAD; b) O Estb Ens possui estrutura de EAD organizada em termos de Divisão/Seção/Núcleo específico de EAD responsável pela gestão acadêmico operacional da modalidade EAD; c) O Estb Ens possui profissionais com conhecimentos e experiência em Planejamento, Projetos e Gestão em EAD; d) $O$ Estb Ens possui sistemática organizada de Avaliação Institucional em EAD, aplicadas de forma contínua e periódica, cujos resultados gerem oportunidades de melhorias (OM) para o processo; e) Há regras instituídas e documentadas que permitam a atuação padrão de competências na EAD definidas para coordenadores de curso/estágio, coordenadores pedagógicos, coordenadores de tutoria, tutores e alunos; f) O Estb Ens dispõe de infraestrutura para controle e distribuição de material didático online, com equipe técnica e dedicada; g) O Estb Ens dispõe de um canal de comunicação aberto para eventuais atendimentos de apoio ao tutor/aluno e h) O Estb Ens dispõe de convênios, parcerias e acordos celebrados com IES/Instituições Educacionais necessárias à execução de EAD.

2. Agentes de ensino: a) O Estb Ens tem política de capacitação de profissionais na modalidade EAD; b) O Estb Ens utiliza apoio de outros estabelecimentos para capacitação dos profissionais de EAD; c) O Estb Ens tem previsão de política de estímulo à produção científica do corpo docente/discente; d) O Estb Ens dispõe de corpo docente com titulação de Doutores, Mestres ou Especialistas de Educação e/ou de EAD; e) O Estb Ens dispõe de corpo docente com profissionais com curso de Psicopedagogia escolar do Centro de Estudos de Pessoal (CEP); f) O Estb Ens libera o profissional de EAD para a realização apenas das atividades docentes quando alocados para Cursos/Estágios nesta modalidade; g) O Estb Ens dispõe de equipe multidisciplinar em EAD; h) O Estb Ens dispõe de profissional com pelo menos 01 ano de qualificação ou experiência em EAD para atuar inclusive na infraestrutura tecnológica de EAD; i) O Estb Ens dispõe de profissional com pelo menos 01 ano de qualificação ou experiência profissional para atuar na produção de material didático para a EAD e j) O Estb Ens dispõe de profissional com pelo menos 01 ano de qualificação ou experiência profissional para atuar na gestão de biblioteca seja física ou virtual.

3. Instalações Físicas: a) O Estb Ens possui instalações físicas próprias para utilização da modalidade EAD (salas de reunião de equipe, salas de tutoria e laboratórios com internet para viabilizar acesso dos alunos ao AVA); b) O Estb Ens possui instalações e equipe própria para a elaboração de recursos de multimídia (audiovisuais, som e TICS); c) O Plano Diretor de Tecnologia da Informação (PDTI) do Estb Ens contempla o plano de expansão e atualização dos equipamentos usados para as atividades de EAD; d) $O$ Estb Ens dispõe de acervo na biblioteca física ou a distância de publicações pertinentes 
a EAD para consulta dos alunos/tutores; e) O Estb Ens possui controle informatizado do acervo da biblioteca e f) $\mathrm{O}$ Est Ens tem previsão de política de aquisição/expansão e atualização do acervo de publicações a distância.

4. Legal e Normativa: a) O Estb Ens dispõe de documentos que validam a legalidade da oferta do Curso/Estágio de EAD (Portaria de criação/Funcionamento/ Normatização e Instruções Reguladoras (IRISM, IRCAM e IROFM)) e b) O Estb Ens dispõe de documentos de ensino nas categorias: ensino por objetivos e/ou por competências na modalidade EAD.

5. Pedagógica: a) O Estb Ens possui o documento de Desenho Didático (Design Instrucional) para EAD publicado em Boletim; b) O Estb Ens possui um Sistema de Tutoria desenvolvido e atuante, subdividido em coordenação de tutoria e tutoria; c) A tutoria do Estb Ens em sua prática didática privilegia a construção do conhecimento e a autonomia do aluno; d) O Estb Ens preocupa-se em manter a níveis adequados de mediação pedagógica do conhecimento (até 30 alunos no máximo) a relação de $n^{\circ}$ de alunos por tutor; e) Os tutores do Estb Ens têm no mínimo 01 ano de qualificação ou experiência comprovados; f) O material didático dos Cursos/Estágios do Estb Ens na modalidade EAD privilegia a interação, o diálogo e os desdobramentos textuais que interagem com o aluno - material multimídia especialmente criado para EAD; g) 0 processo de avaliação dos Cursos/Estágios do Estb Ens na modalidade EAD privilegia os três tipos de avaliação: diagnóstica, formativa e somativa como forma de obtenção de resultados do aprendizado do aluno e h) Os atributos afetivos dos Cursos/Estágios do Estb Ens na modalidade EAD tem o desenvolvimento viabilizado através do ambiente interativo em sala de aula.

Do exposto, após coleta de dados, serão, como citado, gerados planos de ação de ação, contendo ações relacionadas à dimensão organização institucional para EAD do tipo: acompanhamento e controle sobre o projeto pedagógico, sua construção e/ou atualização; revisão dos quadros de cargos e quadros de cargos previstos (QC/QCP); importância dos processos de comunicação com os alunos, dentre outros. Quanto aos agentes de ensino (profissionais com papéis educativos ou de gestão) serão geradas ações que vão compor as políticas de capacitação de pessoal da modalidade EAD, considerados os vários perfis para o desempenho de função na modalidade. No tocante às instalações físicas que compõem a infraestrutura a disposição da EAD serão geradas ações que preveem gastos e alocação de recursos mais racionais, a serem disponibilizados para o Estb Ens/ OM com encargos de ensino, uma vez que todos os recursos financeiros devem ser relacionados no ano anterior para sua utilização. Por fim, no tocante às questões legais e normativas institucionais e as diretrizes pedagógicas, 
tem-se uma engrenagem de atualização, revisão e composição de normativas que permitam realizar as atividades no padrão de excelência e eficácia esperados.

\section{Considerações finais.}

Compreende-se que o SEE do Exército possui uma estrutura complexa de Educação, em termos de peculiaridades, desafios e multiplicidade de modalidades e formas a serem conduzidas, seja no ensino presencial ou a distância. Cada órgão que compõe o SEE possui um rol de responsabilidades específicas em processos educativos, sendo composto, portanto, por Departamento, Diretorias, Estb Ens e OM com encargos de ensino, espalhados pelo país inteiro. Isto significa dizer que um instrumento de pesquisa tal como um checklist de Avaliação da Qualidade de cursos, estágios e programas na EAD como Mecanismo de Melhoria da Gestão de cursos nesta modalidade no EB, precisará ser abrangente o suficiente para abarcar as modalidades de ensino, tais como: formação; graduação; especialização; extensão; aperfeiçoamento; altos estudos militares e preparação e suas peculiaridades e as formas de condução: presencial e a distância, mas também deverá conter as peculiaridades de cada grau, linha e ciclo de ensino, visando melhor qualificar os recursos humanos para a ocupação de cargos e para o desempenho de funções previstas no EB.

As expectativas sobre a aplicação do instrumento citado remete à grandes possibilidades de ajustes no planejamento inicial, uma vez que o cenário a ser pesquisado é de fato bastante complexo, e contém aspectos de melhoria que por inferência hoje, requerem o desenvolvimento de ações coordenadas e correlacionadas à melhoria dos processos da modalidade a distância.

Este artigo visou apresentar parte da metodologia do SAQ-EAD EB e o Checklist (tabela) utilizado para levantar dados dos processos de EAD nos Estb Ens e/ou OM com encargos de ensino, consequentemente apresentar a forma como o Exército através do CEADEx estabelece e conduz sua política de qualidade (SAQ - EAD EB) visando atender à melhoria da qualidade dos processos e produtos gerados na EAD. Assim, 0 Exército Brasileiro cumpre seu papel junto à sociedade, quando com transparência e racionalização de processos, busca a melhoria da educação a seu encargo, dando sua contribuição à educação corporativa, ensino profissionalizante no país.

\section{BIBLIOGRAFIA}

BRASIL, Lei № 9.786, de 08 de fevereiro de 1999. Dispõe sobre o Ensino no Exército Brasileiro. Disponível em: <https://bit.ly/2IFY9vu>. Acesso em 20 abr 2018. 
EXÉRCITO BRASILEIRO. Diretrizes Gerais para a Educação a Distância no Exército. 2010. Disponível em: <https://bit.ly/2IFatA8>. Acesso em 20 abr 2018.

EXÉRCITO BRASILEIRO. Diretriz para Gestão da Educação e Capacitação dos Recursos Humanos do Exército Brasileiro. 2012. Disponível em: $<$ https://bit.ly/2sddRaz>. Acesso em 20 abr 2018.

EXÉRCITO BRASILEIRO. Define Orientação Técnico Pedagógica aos Estb Ens e/ou OM com encargos de ensino vinculados ao DECEx e estabelece novas atribuições ao Departamento. 2014. Disponível em: <https://bit.ly/2KKNajZZ>. Acesso em 20 abr 2018.

INEP, Censo da Educação Superior 2016. Notas Estatísticas. Disponível em: $<$ https://bit.ly/2F4EOwy $>$. Acesso em 20 abr 2018.

INEP, Censo da Educação Superior 2016. Principais resultados. Disponível em: $<$ https://bit.ly/2G8Pu2M> . Acesso em 20 abr 2018.

MEC, Referenciais de Qualidade para Educação Superior a Distância. Disponível em: <https://bit.ly/1Rhf9Z8>. Acesso em 19 abr 2018.

MEC, Resolução CNE/CES no 1, de 11 de março de 2016. Estabelece Diretrizes e Normas Nacionais para a Oferta de Programas e Cursos de Educação Superior na Modalidade a Distância. Disponível em: <https://bit.ly/2/FHqwt>. Acesso em 20 abr 2018. 